\title{
CROSS-SECTIONAL STUDY ABOUT KNOWLEDGE ON WARNING SIGNS AND RISK FACTORS OF COLON CANCER AMONG THE SUBURBAN POPULATION OF MALAYSIA
}

\author{
Barani Karikalan¹, Sakthi Shathi Selvanathan², Tai May Hun² and Sangeeta Kaur ${ }^{3}$, \\ ${ }^{1}$ Department of Pathology, Faculty of Medicine, Perdana University-Royal College of Surgeons in Ireland, \\ Malaysia \\ ${ }^{2}$ Student, School of Medicine, Perdana University-Royal College of Surgeons in Ireland, Malaysia \\ ${ }^{3}$ Department of Community Health, Faculty of Medicine, Perdana University-Royal College of Surgeons in \\ Ireland, Malaysia
}

Corresponding author: Barani Karikalan

Email: baranisri@gmail.com

\begin{abstract}
Colorectal cancer $(C R C)$ is the third most commonly diagnosed cancer worldwide. This study aimed to determine the knowledge level of CRC signs and risk factors among the multi-ethnic sub-urban population based on age, gender and education attainment levels. A cross-sectional study was carried out among residents of Kuala Selangor and Sabak Bernam from 28 $8^{\text {th }}$ January 2019 till $4^{\text {th }}$ February 2019 by using convenient sampling method. 350 participants were recruited and assessed using validated and modified self-administered Cancer Awareness Measures (CAM) questionnaire which consist of sociodemographic characteristics, knowledge on warning signs and risk factors of CRC. Analysis was performed for symptoms and risk factors awareness against independent variables. The participants of the study are semi-urban population of Malaysia and were able to recognise the CRC symptoms and risk factors, and exhibited an average overall CRC knowledge level. The analysis showed that older age group (age > 50) participants were more familiar with the CRC symptoms and risk factors. Males have a greater percentage in the 'High' level of knowledge category compared to females although there was no significance between gender and knowledge level based on statistical analysis. Education attainment levels were found to be associated with the knowledge level whereby highly educated participants were more aware of the CRC symptoms and risk factors. Knowledge level on CRC symptoms and risk factors was average among the multi-ethnic sub-urban population. Therefore, health awareness programmes on $C R C$ should be tailored to all especially the lower educational attainment groups, females and younger individuals in order to increase their awareness and reduce the CRC incidence.
\end{abstract}

Keywords: Colorectal cancer, Cancer risk factors, Cancer screening

\section{INTRODUCTION}

The third most frequently diagnosed cancer in the world is colorectal cancer (CRC). According to the estimates from International Agency for Research on Cancer (IARC) and World Health Organization GLOBOCAN database, approximately 1.8 million new cases of CRC were diagnosed and almost 861,000 deaths in 2018 were reported respectively, accounting for $10.2 \%$ of global cancer incidence burden ${ }^{1,2}$.

In the past two decades, CRC incidence has drastically increased in developing countries such as Malaysia ${ }^{3}$. The newly released Malaysian National Cancer Registry Report (MNCRR) 20122016 found that the incidence of CRC rose from $13.2 \%(2007-2011)$ to $13.5 \%(2012-2016)$ and it is still ranked within the top three cancer types, affecting both male and female population since 2007, but predominantly males now ${ }^{4,5}$. For instance, the age standardised incidence rates (ASR) for CRC in males and females were 14.8 and 11.1 per 100,000 population respectively. Besides, the lifetime risk for males was 1 in 55 and 1 in 76 for females. The incidence increased with age and peak at the age of 70 and above for both genders.

MNCRR 2012-2016 also documented the cancer cases percentage detected in later stages namely stage 3 and 4 was $63.7 \%$ (2012-2016), higher compared to 2007 - 2011 reports which was $58.7 \%{ }^{4}$. High CRC incidence in Malaysia is noticed among patients $(61.3 \%)$ presented at later stages as well 6 . A higher mortality rate is correlated with patients at these stages because tumour cells has metastasised to lymph nodes and other parts of the body ${ }^{7}$. The limited awareness and knowledge of the disease itself may be the possible reasons for late detection or late or no screening. Hashim et al. documented that amongst $60 \%$ of the patients who have experienced rectal bleeding were unsure of the underlying factor of bleeding thus delayed in seeking treatment and only 2 patients from the study suspected themselves having cancer $^{8}$. This study reflects that the CRC awareness level in the general public is still low and lacking. Similarly, locally, a study on CRC awareness among urban population Klang Valley 
revealed that of the 426 respondents, $29.1 \%$ were unable to recall the CRC symptoms ${ }^{9}$. Another study on CRC awareness level among multi-ethnic rural population in Perak districts displayed that $38 \%$ and $32 \%$ of the respondents had zero knowledge score for symptoms and risk factors respectively ${ }^{10}$. CRC is the third leading cause of cancer-related deaths among Malaysians attributing to $8.55 \%$ mortality in $2018^{1}$. Having said that, the community as a whole must be aware on the CRC symptoms and risk factors as the 5-year survival rate of CRC could be as high as $90 \%$ if it is detected and treated early ${ }^{11}$.

The above evidence has illustrated that CRC knowledge attitude and perception is warranted among the general population. This is because the attitude and opinions of the people towards cancer play a significant role in behavioural and lifestyle modifications in preventing cancer $^{12}$. CRC is a widely preventable disease where about $75 \%$ of the total cases are found to arise sporadically without any inherited predisposition ${ }^{13}$. Hence, preventive measures which chiefly focus on lifestyle modification and participation of the routine medical screening were largely encouraged among the community. Currently, Malaysia is facing the prospect of an aging population with growing prosperity and an increased prevalence of risk factors for CRC, for instance obesity, smoking and western diet. Studies showed that about $80 \%$ of CRC cases in Malaysia are seen in people older than 50 years ${ }^{14-}$ 16. This indicates there is still low CRC knowledge and awareness among the community. Furthermore, it is vital to examine the knowledge level of the people and to elucidate how gender differences correlate to the CRC knowledge status as a whole, specifically to the sub-urban population as there are misconceptions on gender at risk and insufficient knowledge on the symptoms and risk factors. For example, looking into a study among urban African American clinic patients, the misperceptions rate that only men are at risk was higher among those who never screened whereas those who screened had a wider knowledge on the causes and risk factors ${ }^{17}$. However, generally, awareness of the significance of cancer prevention is low which includes among those with lower literacy rates. An earlier study showed that highly educated people practice healthy lifestyle choices as they are more knowledgeable on cancer risk factors ${ }^{18}$.

In short, several works of literature have postulated the influence of certain socio demographic elements on the CRC awareness level ${ }^{18,19,10}$. Therefore, this study was conducted to identify the knowledge gap on CRC among the local population especially the suburban community in terms of age, gender difference and education attainment levels.

\section{METHODS}

\section{Study Setting and Participants}

A sub-urban-based cross-sectional study was carried out among residents from Sabak Bernam and Kuala Selangor for 2 weeks from $28^{\text {th }}$ January 2019 to $4^{\text {th }}$ February 2019. The population in both districts were estimated to range within 100,000 and 120,000 in 2015 and based on the assumptions that $40 \%$ of the population will fall within the age range of the study sample with $95 \%$ confidence interval, the calculated sample size was 350 participants. This study was approved by the Institutional Review Board of Perdana University (PU IRBHR0196). Convenience sampling method was used where subjects were approached in the commercial or public area in the specific localities.

\section{Study Tool}

The CRC awareness level was accessed by using self-administered questionnaires that were based on Colorectal Cancer Awareness Measure (Colorectal CAM) which was developed by University College London and Cancer Research UK. There are 3 sections in this questionnaire which includes socio-demographic characteristics, awareness on symptoms and awareness of CRC risk factors. The survey instrument was translated into Bahasa Malaysia and Mandarin. Forward and backward translation was performed by independent individuals and examined by PU-RCSI academics. The study is validated by pilot testing to suit for Malaysian context. A total of 500 individuals were approached and based on inclusion and exclusion criteria, 350 participants were recruited. The participants were Malaysian residing in the study areas and the age range was 18-60 years old. Vulnerable populations such as adults who are unable to consent, children and pregnant women were excluded hence leading to a response rate of $70 \%$.

\section{Knowledge of signs and symptoms and risk factors of colorectal cancer}

The self-administered questionnaire was divided into two sections, first prompting participants with a closed-ended question to assess the degree of understanding of CRC signs and risk factors respectively. The stem question is phrased as; "Which one do you think are the warning signs and symptoms of colon cancer?" It is the same in section 2 . This is followed by a list of 9 symptoms in section $A$ and 13 risk factors in section $B$. A scoring system for the knowledge was applied where 1 point is given to each selected symptom and risk factor.

\section{Description of variables}

The total knowledge score for signs and risk factors of CRC ranges from 0 to 9 and 0 to 10 respectively. Other variables were sociodemographic characteristics. 


\section{Process of data collection}

Participants were approached and provided with the study overview, upon obtaining an interest in participation, the participants were asked to provide written consent. Participants were approached in general/public vicinities in Kuala Selangor and Sabak Bernam. The participants took about 5-7 minutes to complete the selfadministered questionnaires.

\section{Statistical Analysis}

Collected data was entered and analysed using the IBM Statistical Packages for Social Science
(SPSS) Statistics software Version 23. Descriptive and univariate analysis were done. Skewness and kurtosis of the data were assessed and frequencies for each categorical variable was then obtained. A scoring system was established to categorise the variables. Frequency tables for independent variables were tabulated and were evaluated against CRC knowledge level using chisquared test to highlight significant $(p=0.05)$ results of the study. Analysis was performed for awareness of symptoms and risk factors separately against independent variable.

The scoring system is as follow

\begin{tabular}{lll}
\hline Sign and Symptoms & Risk Factors & $\begin{array}{l}\text { Total Score (Sign and Risk } \\
\text { Factors) }\end{array}$ \\
\hline $0-2=1$ & $0-3=1$ & $0-2=$ low \\
$3-4=2$ & $4-6=2$ & $\begin{array}{l}3-5=\text { moderate } \\
6-8=\text { high }\end{array}$ \\
$5-6=3$ & $7-9=3$ & \\
$7-9=4$ & $10-13=4$ & \\
\hline
\end{tabular}

\section{RESULTS}

A total of 372 participants consented but only 350 (154 from Sabak Bernam and 196 from Kuala Selangor) participants were recruited as they had their questionnaires filled up completely. Table 1 shows the baseline demographics of the study population; The mean age of the 350 respondents was 31 years old, with $56.9 \%$ were from the age group of $18-29$ years old. This study showed the female population and Malay ethnic group dominated their respective category by giving a percentage of $56.3 \%$ and $82.6 \%$ respectively. $51.4 \%$ of the total participants were single while $54.9 \%$ of the total participants had an up to high school level of education. Majority of the respondents $(75.7 \%)$ had a monthly household income of less than RM3000.

Table 1. Socio-demographic characteristics among respondents from Sabak Bernam and Kuala

\begin{tabular}{llcc}
\hline Socio-demographic characteristics & & N (=350) & Percentages (\%) \\
\hline Age & $18-29$ years old & 199 & 56.9 \\
& $30-49$ years old & 105 & 30.0 \\
Gender & $>50$ years old & 46 & 13.1 \\
Ethnicity & Male & 153 & 43.7 \\
& Female & 197 & 56.3 \\
& Malay & 289 & 82.6 \\
Marital Status & Chinese & 23 & 6.6 \\
& Indian & 35 & 10.0 \\
& Others & 3 & 0.9 \\
Level of Education & Single & 180 & 51.4 \\
& Married & 162 & 46.3 \\
\multirow{3}{*}{ Monthly Household Income } & Widower & 8 & 2.3 \\
& Primary/Secondary & 192 & 54.9 \\
& Diploma/ Certificate & 90 & 25.7 \\
& Degree/ Post-graduate & 68 & 19.4 \\
& $<$ RM3000 & 265 & 75.7 \\
& RM3001-5000 & 31 & 8.9 \\
\hline
\end{tabular}


Table 2. Relationship between age and knowledge of warning signs of colorectal cancer

\begin{tabular}{lllll}
\hline Signs and Symptoms & \multicolumn{3}{c}{ Age } & p- \\
\cline { 2 - 4 } & $18-29$ & $30-49$ & $>50$ & value \\
\hline Abdominal pain & $124(62.3 \%)$ & $72(68.6 \%)$ & $35(76.1 \%)$ & 0.165 \\
Blood in stool & $117(58.8 \%)$ & $65(61.9 \%)$ & $27(58.7 \%)$ & 0.861 \\
Bleeding from back passage & $82(41.2 \%)$ & $51(48.6 \%)$ & $21(45.7 \%)$ & 0.456 \\
Change in bowel habit & $71(35.7 \%)$ & $45(42.9 \%)$ & $18(39.1 \%)$ & 0.469 \\
Feeling of incomplete emptiness & $52(26.0 \%)$ & $41(39.0 \%)$ & $19(41.0 \%)$ & 0.025 \\
Unexplained weight loss & $63(31.0 \%)$ & $57(54.0 \%)$ & $24(52.0 \%)$ & 0.000 \\
Tiredness or anaemic & $59(29.0 \%)$ & $46(43.0 \%)$ & $26(56.0 \%)$ & 0.001 \\
Lump in abdomen & $76(38.2 \%)$ & $47(44.8 \%)$ & $14(30.4 \%)$ & 0.231 \\
Back passage pain & $69(34.7 \%)$ & $41(39.0 \%)$ & $15(32.6 \%)$ & 0.672 \\
\hline
\end{tabular}

Table 2 and 3 present the cross-tabulation for analysis of the relationship between age and knowledge of CRC symptoms and risk factors respectively. The analysis showed that older age group (age > 50) participants were more familiar with the CRC warning signs and risk factors. "Abdominal pain" and "Low fruit/vegetable intake" were the most commonly picked-up symptoms and risk factors respectively by all age group participants. From the list of signs and symptoms stated above, "Feeling of incomplete emptiness" $(p=0.025)$, "Unexplained weight loss" $(p=0.000)$ and "Tiredness or anaemic" $(p=0.001)$ had a significant relationship with the age of the participants as the $\mathrm{p}$-value is less than 0.05 . Similarly, risk factors, for instance, "Smoking" $(p=0.016)$, "High intake of red/processed meat" $(p=0.004)$, "Older age" $(p=0.006)$, "Consume raw fish/seafood" ( $p=0.003)$ and "Having diabetes" $(p=0.002)$ were documented to have a significant association with age.

Table 3. Relationship between age and knowledge of risk factors of colorectal cancer

\begin{tabular}{lllll}
\hline Risk Factors & \multicolumn{3}{c}{ Age } & $\begin{array}{c}\text { p- } \\
\text { value }\end{array}$ \\
\cline { 2 - 5 } & $18-29$ & $30-49$ & $>50$ & 0.089 \\
Low intake of fruits/ vegetables & $117(58.8 \%)$ & $63(60.0 \%)$ & $35(76.1 \%)$ & 0.800 \\
Low fibre diet & $110(55.2 \%)$ & $58(55.2 \%)$ & $23(50.0 \%)$ & 0.004 \\
High intake of red/ processed meat & $70(35.7 \%)$ & $56(53.3 \%)$ & $24(52.2 \%)$ & 0.535 \\
Alcohol consumption & $87(43.7 \%)$ & $52(49.5 \%)$ & $19(41.3 \%)$ & 0.264 \\
Low physical activity & $58(29.1 \%)$ & $35(33.3 \%)$ & $19(41.3 \%)$ & 0.710 \\
Family history of having bowel cancer & $85(42.7 \%)$ & $50(47.6 \%)$ & $20(43.5 \%)$ & 0.006 \\
Older age & $29(14.0 \%)$ & $19(18.0 \%)$ & $16(34.0 \%)$ & 0.587 \\
Being overweight or obese & $60(30.2 \%)$ & $36(34.3 \%)$ & $17(36.9 \%)$ & 0.861 \\
Having other bowel disease & $70(35.2 \%)$ & $39(37.1 \%)$ & $18(39.1 \%)$ & 0.002 \\
Having diabetes & $23(11.6 \%)$ & $17(16.2 \%)$ & $15(32.6 \%)$ & 0.003 \\
Consume raw fish/ seafood & $35(17.6 \%)$ & $34(32.4 \%)$ & $16(34.8 \%)$ & 0.016 \\
Smoking & $67(33.7 \%)$ & $41(39.0 \%)$ & $26(56.5 \%)$ & 0.766 \\
Previous history of colon cancer & $90(45.2 \%)$ & $44(41.9 \%)$ & $22(47.8 \%)$ & \\
\hline
\end{tabular}

Table 4. Relationship between gender and knowledge of warning signs of colorectal cancer

\begin{tabular}{lll}
\hline \multicolumn{1}{c}{ Signs and Symptoms } & \multicolumn{1}{c}{ Gender } \\
\cline { 2 - 3 } Abdominal pain & Male & Female \\
Blood in stool & $106(63.3 \%)$ & $125(63.5 \%)$ \\
Bleeding from back passage & $96(62.7 \%)$ & $113(57.4 \%)$ \\
Change in bowel habit & $65(42.5 \%)$ & $89(45.2 \%)$ \\
Feeling of incomplete emptiness & $60(32.9 \%)$ & $74(37.6 \%)$ \\
Unexplained weight loss & $53(34.6 \%)$ & $59(29.9 \%)$ \\
Tiredness or anemic & $69(45.1 \%)$ & $75(38.1 \%)$ \\
Lump in abdomen & $63(41.2 \%)$ & $68(34.5 \%)$ \\
Back passage pain & $58(38.0 \%)$ & $79(40.1 \%)$ \\
& $62(40.5 \%)$ & $63(32.0 \%)$
\end{tabular}


The cross-tabulation for analysis of the relationship between gender and knowledge of warning signs and risk factors of CRC respectively can be seen in table 4 and 5 . The most frequently recalled warning sign and risk factor are "Abdominal pain" and "Low fruit/vegetable intake" respectively by both gender.
Table 6 shows male participants (15.7\%) predominately had a score of 2 which means most of them selected 3-4 out of 9 symptoms whereas $20.3 \%$ of female participants scored 1 in which most of them marked 0-2 symptoms out of 9 . However, females account for a higher percentage compared to males in a maximum score of 4 . There is no significant difference between the two variables since $p=0.289$.

Table 5 Relationship between gender and knowledge of risk factors of colorectal cancer

\begin{tabular}{lll}
\hline Risk Factors & \multicolumn{2}{c}{ Gender } \\
\cline { 2 - 3 } Low intake of fruits/ vegetables & Male & Female \\
Low fibre diet & $101(66.0 \%)$ & $114(57.9 \%)$ \\
High intake of red/ processed meat & $88(57.5 \%)$ & $103(52.3 \%)$ \\
Alcohol consumption & $68(44.4 \%)$ & $82(41.6 \%)$ \\
Low physical activity & $77(50.3 \%)$ & $81(41.1 \%)$ \\
Family history of having bowel cancer & $56(36.6 \%)$ & $56(28.4 \%)$ \\
Older age & $68(44.4 \%)$ & $87(44.2 \%)$ \\
Being overweight or obese & $32(20.9 \%)$ & $32(16.2 \%)$ \\
Having other bowel disease & $51(33.3 \%)$ & $62(31.2 \%)$ \\
Having diabetes & $57(37.3 \%)$ & $70(35.5 \%)$ \\
Consume raw fish/ seafood & $30(19.6 \%)$ & $25(12.7 \%)$ \\
Smoking & $33(21.6 \%)$ & $52(26.4 \%)$ \\
Previous history of colon cancer & $70(45.8 \%)$ & $64(32.5 \%)$ \\
\hline
\end{tabular}

Table 7 shows the majority males $(16.6 \%)$ had obtained a score of 2 which means they were able to recognize 4-6 risk factors out of 13 . Majority females $(25.1 \%)$ marked $0-3$ risk factors and scored 1. However, more males obtained the highest score of 4 . P-value being 0.075 indicates no significant difference between the two variables. Table 8 and 9 display the crosstabulation for analysis of the relationship between educational level and knowledge on warning signs and risk factors of CRC respectively. Participants with higher education level as in with at least a degree qualification were more aware of the warning signs and risk factors of CRC. "Blood in stool" was the most commonly recognized warning sign whereas "Low fibre diet" was the most frequently recalled risk factor among $79.4 \%$ and $77.9 \%$ of the degree level educated participants respectively. While among high school and diploma qualifiers, "Abdominal pain" and "Low intake of fruits/vegetables" were the most frequently selected sign and risk factor respectively. Only "Blood in stanl" $(p=0.001)$ and "Tiredness or anaem $8.9 \%$ J.025) had a significant correlation witn the education level of the participants as the $p<0.05$. Relationship between educational level and the risk factors such as "Low fibre diet" $(\mathrm{p}<0.01)$, "Having diabetes" $(p=0.017)$ and "The previous history of colon cancer" $(p=0.03)$ was found to be significant too.

Table 6. Scores for Signs and Symptoms in different genders

\begin{tabular}{lccccc}
\hline Gender & \multicolumn{2}{l}{ Scores for Signs \& Symptoms $(\mathrm{n}=\%)$} & p-value \\
\cline { 2 - 5 } & \multicolumn{2}{c}{1} & 2 & 3 & 4 \\
\hline Male & $41(11.7 \%)$ & $55(15.7 \%)$ & $34(9.7 \%)$ & $23(6.6 \%)$ & 0.289 \\
\multirow{2}{*}{ Female } & $71(20.3 \%)$ & $59(16.9 \%)$ & $37(10.6 \%)$ & $30(8.6 \%)$ & \\
\hline
\end{tabular}


Malaysian Journal of Public Health Medicine 2021, Vol. 21 (1): 103-111

Table 7 Scores for risk factors in different genders

\begin{tabular}{|c|c|c|c|c|c|}
\hline \multirow[t]{2}{*}{ Gender } & \multicolumn{3}{|c|}{ Scores for Risk Factors } & & \multirow[t]{2}{*}{ p-value } \\
\hline & 1 & 2 & 3 & 4 & \\
\hline Male & $49(14.0 \%)$ & $58(16.6 \%)$ & $30(8.6 \%)$ & $16(4.6 \%)$ & 0.075 \\
\hline Female & $88(25.1 \%)$ & $67(19.1 \%)$ & $30(8.6 \%)$ & $12(3.4 \%)$ & \\
\hline
\end{tabular}

Table 8 Relationship between education level and knowledge of warning signs of colorectal cancer

\begin{tabular}{lllll}
\hline \multirow{2}{*}{ Signs and Symptoms } & \multicolumn{3}{c}{ Education Level } & $\begin{array}{l}\text { p- } \\
\text { value }\end{array}$ \\
\cline { 2 - 4 } & $\begin{array}{l}\text { Primary/ } \\
\text { Secondary }\end{array}$ & $\begin{array}{l}\text { Diploma/ } \\
\text { Certificate }\end{array}$ & $\begin{array}{l}\text { Degree/ Post- } \\
\text { graduate }\end{array}$ & \\
\hline Abdominal pain & $126(65.6 \%)$ & $55(61.1 \%)$ & $50(73.5 \%)$ & 0.261 \\
Blood in stool & $\mathbf{1 0 5 ( 5 4 . 7 \% )}$ & $\mathbf{5 0 ( 5 5 . 6 \% )}$ & $\mathbf{5 4}(\mathbf{7 9 . 4 \% )}$ & $\mathbf{0 . 0 0 1}$ \\
Bleeding from back passage & $81(42.2 \%)$ & $36(40.0 \%)$ & $37(54.4 \%)$ & 0.147 \\
Change in bowel habit & $67(34.9 \%)$ & $33(36.7 \%)$ & $34(50.0 \%)$ & 0.083 \\
Feeling of incomplete emptiness & $55(28.6 \%)$ & $28(31.1 \%)$ & $29(42.6 \%)$ & 0.102 \\
Unexplained weight loss & $77(40.1 \%)$ & $33(36.7 \%)$ & $34(50.0 \%)$ & 0.219 \\
Tiredness or anaemic & $71(37.0 \%)$ & $26(28.9 \%)$ & $34(50.0 \%)$ & 0.025 \\
Lump in abdomen & $72(37.5 \%)$ & $35(38.9 \%)$ & $30(44.1 \%)$ & 0.629 \\
Back passage pain & $69(35.9 \%)$ & $25(27.8 \%)$ & $31(45.6 \%)$ & 0.069 \\
\hline
\end{tabular}

Table 9 Relationship between education level and knowledge of risk factors of colorectal cancer

\begin{tabular}{lllll}
\hline Risk Factors & \multicolumn{3}{c}{ Education Level } \\
\cline { 2 - 4 } & $\begin{array}{l}\text { Primary/ } \\
\text { Secondary }\end{array}$ & $\begin{array}{l}\text { Diploma/ } \\
\text { Certificate }\end{array}$ & $\begin{array}{l}\text { Degree/ Post- } \\
\text { graduate }\end{array}$ & value \\
\hline Low intake of fruits/ vegetables & $111(57.8 \%)$ & $54(60.0 \%)$ & $50(73.5 \%)$ & 0.069 \\
Low fibre diet & $\mathbf{9 3 ( 4 8 . 4 \% )}$ & $\mathbf{4 5 ( 5 0 . 0 \% )}$ & $\mathbf{5 3}(\mathbf{7 7 . 9 \% )}$ & $<0.01$ \\
High intake of red/ processed meat & $79(41.1 \%)$ & $36(40.0 \%)$ & $35(51.5 \%)$ & 0.274 \\
Alcohol consumption & $86(44.8 \%)$ & $41(45.6 \%)$ & $31(45.6 \%)$ & 0.989 \\
Low physical activity & $64(33.3 \%)$ & $23(25.6 \%)$ & $25(36.8 \%)$ & 0.275 \\
Family history of having bowel cancer & $76(39.6 \%)$ & $44(48.9 \%)$ & $35(51.5 \%)$ & 0.141 \\
Older age & $30(15.6 \%)$ & $18(20.0 \%)$ & $16(23.5 \%)$ & 0.311 \\
Being overweight or obese & $62(32.3 \%)$ & $28(31.1 \%)$ & $23(33.8 \%)$ & 0.937 \\
Having other bowel disease & $64(33.3 \%)$ & $30(33.3 \%)$ & $33(48.5 \%)$ & 0.065 \\
Having diabetes & $\mathbf{3 5 ( 1 8 . 2 \% )}$ & $\mathbf{1 7}(18.9 \%)$ & $\mathbf{3}(\mathbf{4 . 4 \% )}$ & 0.017 \\
Consume raw fish/ seafood & $52(27.1 \%)$ & $17(18.9 \%)$ & $16(23.5 \%)$ & 0.322 \\
Smoking & $68(35.4 \%)$ & $40(44.4 \%)$ & $26(38.2 \%)$ & 0.348 \\
Previous history of colon cancer & $\mathbf{7 8 ( 4 0 . 6 \% )}$ & $\mathbf{3 8 ( 4 2 . 2 \% )}$ & $\mathbf{4 0}(\mathbf{5 8 . 8 \%})$ & $\mathbf{0 . 0 3 0}$ \\
\hline
\end{tabular}

\section{DISCUSSION}

Knowledge of CRC symptoms and risk factors plays a vital role in early detection and diagnosis of the disease. For instance, "Abdominal pain" was the third most frequent warning sign in CRC patients according to the Kuala Lumpur (KL) tertiary referral center study ${ }^{20}$. This finding corresponds to our study, where "Abdominal pain" was the most common symptom selected by all age participants, gender and participants with at least diploma qualification. It is possible that this population perceived abdominal pain to be related to CRC due to anatomical location ${ }^{9}$. Earlier studies suggested that recognition and understanding of the potential seriousness of those symptoms is more important than patients' awareness of symptoms ${ }^{21}$. This is because early diagnosis of CRC is fully dependent on individualized effort on getting themselves screened either via endoscopic or non-endoscopic methods based on the signs recognized ${ }^{22}$.

Environmental and genetics risk factors can increase the chances of developing $\mathrm{CRC}^{23}$. Diabetes mellitus is a good example. A metaanalysis of 14 studies estimated that the risk of CRC among diabetics was roughly $38 \%$ higher than it was for non-diabetics ${ }^{24}$. However, "Having diabetes" was the least recognised risk factor among this population which is similar with UK findings ${ }^{25}$. Diabetes mellitus prevalence rate in 
adults (20-79 years) was $16.7 \%$ and 3.6 million cases were documented in Malaysia in $2019^{26}$. Thus, this is a clear indication for everyone, especially the healthcare professionals to actively educate the public on the importance of balanced diet intake and regarding the risk of CRC in diabetics 9 .

Older age group populations have better knowledge regarding CRC symptoms and risk factors than younger individuals according to the current study. As people age, they become more health conscious, tend to acquire more knowledge from various resources to increase awareness and pay attention to the diseases that might plague them, such as CRC. Therefore, unsurprisingly, they recognize more CRC symptoms compared to the younger participants even after adjusting according to socioeconomic group, ethnicity and gender. Based on the current study analysis, males have higher CRC knowledge level than females which is corroborated with Hyoung-Chul Park et al (2013) findings ${ }^{27}$.

Our current research demonstrates an average overall CRC knowledge level among semi-urban populations. This finding was in consistent with the earlier study conducted in Perak, which reported that participants living in a rural area were unaware of the CRC signs ${ }^{28}$, but was in contrast with the study conducted among urban community in Klang Valley whereby most of the participants could recognise at least one correct symptom ${ }^{9}$. The fact that the urban population is better educated and exposed more to health promotions regarding the CRC risk factors could be the reason behind the different levels of awareness between urban population and rural population?.

Role of screening should be given importance to further reduce the CRC burden along with imparting awareness among people through various health programmes or advertisements via social media platforms. Studies showed that the current high-risk Asian countries for CRC have widespread of faecal occult blood testing (FOBT) screening and colonoscopy triage of screenpositive individuals on going over the last two decades and CRC mortality has started declining due to improved early detection through screening and improved access to surgery and adjuvant chemotherapy despite increasing incidence in these countries ${ }^{29}$. In the near future, hopefully, Machine Learning (ML) an application which automatically learns and accesses patients' digital health records and high-volume information extraction from medical images can play an essential role in oncology screening strategies which includes CRC screening and provide suitable prognosis and therapy ${ }^{30}$.

\section{Limitations of Study}

There were several shortcomings exhibited in this study. The sample population could be small as this study was conducted in a short duration. The CRC knowledge level of the urban population was not explored due to results being limited to semiurban population in this study. Hence, the findings obtained are not representative of the whole Malaysia population.

\section{CONCLUSION}

In short, the knowledge level of CRC symptoms and risk factors is average among semi-urban population. CRC is a devastating health problem which is increasingly impacting the population in our country. Therefore, health awareness programmes which include CRC Awareness Day which falls in March should be highlighted and conducted frequently, targeting all especially the lower educational attainment groups, females and younger individuals in order to increase their awareness and reduce the CRC incidence together.

\section{Conflict of interest}

The authors declare no potential conflict of interest.

\section{REFERENCES}

1. Global Cancer Observatory [Internet]. [cited 2020 Apr 20]. Available from: http://gco.iarc.fr/

2. Wolf AMD, Fontham ETH, Church TR, Flowers CR, Guerra CE, LaMonte SJ, et al. Colorectal cancer screening for average-risk adults: 2018 guideline update from the American Cancer Society: ACS Colorectal Cancer Screening Guideline. CA Cancer J Clin. 2018 Jul;68(4):250-81.

3. Bishehsari F, Mahdavinia M, Vacca $M$, Malekzadeh R, Mariani-Costantini R. Epidemiological transition of colorectal cancer in developing countries: Environmental factors, molecular pathways, and opportunities for prevention. World $\mathrm{J}$ Gastroenterol WJG. $2014 \quad$ May 28;20(20):6055-72.

4. Azizah $A M$ HB Nirmal $K$, Siti Zubaidah AR, Puteri NA, Nabihah A, Sukumaran R, Balqis B, Nadia SMR, Sharifah SSS, Rahayu O, Nur Alham 0, Azlina AA. MNCR 2012-2016 FINAL (PUBLISHED 2019).pdf [Internet]. 2019 Jun [cited 2020 Apr 20] p. 34-7. Available from: https: //drive.google.com/file/u/1/d/1BuP Wrb05N2Jez6sEP8VM5r6JtJtIPN5W/view? usp =sharing\&usp=embed_facebook

5. Azizah AM Nor Saleha I, Noor Hashimah A, Asmah Z, Mastulu W. Malaysian National Cancer Registry Report 2007-2011.pdf [Internet]. No 4, Jalan P7, Presint 7, 62250 Putrajaya, MALAYSIA: The National Cancer Institute; 2016 [cited 2020 Apr 18] p. 36-8. 
Available

from:

https: / /drive.google.com/file/u/1/d/1pCsJl w0ysFccCMFA0XqzfbYu1OFDRbO_/view?usp= sharing\&usp=embed_facebook

6. Abu Hassan MR, Ismail I, Mohd Suan MA, Ahmad F, Wan Khazim WK, Othman Z, et al. Incidence and mortality rates of colorectal cancer in Malaysia. Epidemiol Health [Internet]. 2016 Mar 9 [cited 2020 Apr 18];38. Available

from: https: / /www.ncbi.nlm.nih.gov/pmc/articles /PMC5081307/

7. Holland-Frei Cancer Medicine. 6th ed. BC Decker; 2003.

8. Mohd Hashim S, Tong SF, Omar K, Rashid MR, Shah SA, Sagap I. Knowledge of Colorectal Cancer among Patients Presenting with Rectal Bleeding and its Association with Delay in Seeking Medical Advice. Asian Pac J Cancer Prev APJCP. 2011 Jan 1;12:2007-11.

9. Sindhu C, Nijar A, Leong P, Li Z, Hong C, Malar L, et al. Awareness of Colorectal Cancer among the Urban Population in the Klang Valley. Malays Fam Physician Off J Acad Fam Physicians Malays. 2019 Dec 31;14(3):1827.

10.Su TT, Goh JY, Tan J, Muhaimah AR, Pigeneswaren $\mathrm{Y}$, Khairun NS, et al. Level of colorectal cancer awareness: a cross sectional exploratory study among multiethnic rural population in Malaysia. BMC Cancer. 2013 Aug 7;13(1):376.

11.Moghimi-Dehkordi B, Safaee A. An overview of colorectal cancer survival rates and prognosis in Asia. World J Gastrointest Oncol. 2012 Apr 15;4(4):71-5.

12. Kloosterboer SM, Brekel $\mathrm{K}$ van den, Rengers $\mathrm{AH}$, Peek N, Wit NJ de. An exploration of beliefs and attitudes regarding healthy lifestyle behaviour in an urban population in The Netherlands: Results from a focus group study in a community-based prevention project. Eur J Public Health. 2015;

13. Yamagishi $H$, Kuroda $H$, Imai $Y$, Hiraishi $H$. Molecular pathogenesis of sporadic colorectal cancers. Chin J Cancer [Internet]. 2016 Jan 6 [cited 2020 Apr 18];35. Available from:

https://www.ncbi.nlm.nih.gov/pmc/articles /PMC4704376/

14. Malaysia: aging population 2019 [Internet]. Statista. [cited 2020 Apr 18]. Available from: https://www.statista.com/statistics/713529 /malaysia-aging-population/

15.Sung JJY, Ng SC, Chan FKL, Chiu HM, Kim HS, Matsuda T, et al. An updated Asia Pacific
Consensus Recommendations on colorectal cancer screening. Gut. 2015 Jan 1;64(1):12132.

16. Center MM, Jemal A, Smith RA, Ward E. Worldwide Variations in Colorectal Cancer. CA Cancer J Clin. 2009 Nov 1;59(6):366-78.

17.Wong MCS, Hirai HW, Luk AKC, Lam TYT, Ching JYL, Griffiths SM, et al. The Knowledge of Colorectal Cancer Symptoms and Risk Factors among 10,078 Screening Participants: Are High Risk Individuals More Knowledgeable? PLOS ONE. 2013 Apr 3;8(4):e60366.

18.Pan $Y$, jin yu $C$, Haris A, Yuan A. Assessment of the level of knowledge of colorectal cancer among public at outpatient clinics in Serdang Hospital: a survey based study. Med J Malaysia. 2017 Dec 6;72:338-44.

19. Winterich JA, Quandt SA, Grzywacz JG, Clark $P$, Dignan M, Stewart JH, et al. Men's Knowledge and Beliefs about Colorectal Cancer and Three Screenings: Education, Race and Screening Status. Am J Health Behav. 2011 Sep;35(5):525-34.

20.Mohd Radzniwan A Rashid1 Aznida Firzah Abdul Aziz1, Saharuddin Ahmad1, Shamsul Azhar Shah2, Ismail Sagap3*. Asian Pacific Journal of Cancer Prevention. Asian Pac J Cancer Prev. 2009;10:1163-6.

21. Mitchell E, Macdonald S, Campbell NC, Weller D, Macleod U. Influences on pre-hospital delay in the diagnosis of colorectal cancer: a systematic review. $\mathrm{Br} \mathrm{J}$ Cancer. 2008 Jan 15;98(1):60-70.

22. Khayyat YM, Ibrahim EM. Public awareness of colon cancer screening among the general population: A study from the Western Region of Saudi Arabia. Qatar Med J. 2014;2014(1):17-24.

23. Chan AT, Giovannucci EL. Primary Prevention of Colorectal Cancer. Gastroenterology. 2010 Jun;138(6):2029-2043.e10.

24. Yuhara H, Steinmaus C, Cohen SE, Corley DA, Tei Y, Buffler PA. Is Diabetes Mellitus an Independent Risk Factor for Colon Cancer and Rectal Cancer? Am J Gastroenterol. 2011 Nov;106(11):1911-22.

25.Power E, Simon A, Juszczyk D, Hiom S, Wardle J. Assessing awareness of colorectal cancer symptoms: Measure development and results from a population survey in the UK. BMC Cancer. 2011 Aug 23;11:366.

26.Malaysia diabetes report 2010 - 2045 [Internet]. [cited 2020 Apr 17]. Available from: https://www.diabetesatlas.org/data/ 
27.Park H-C, Shin A, Kim B-W, Jung K-W, Won Y$\mathrm{J}$, Oh $\mathrm{JH}$, et al. Data on the Characteristics and the Survival of Korean Patients With Colorectal Cancer From the Korea Central Cancer Registry. Ann Coloproctology. 2013 Aug;29(4):144-9.

28.Su TT, Goh JY, Tan J, Muhaimah AR, Pigeneswaren $\mathrm{Y}$, Khairun NS, et al. Level of colorectal cancer awareness: a cross sectional exploratory study among multiethnic rural population in Malaysia. BMC Cancer. 2013 Aug 7;13(1):376.
29.Shin A, Jung K-W, Won Y-J. Colorectal cancer mortality in Hong Kong of China, Japan, South Korea, and Singapore. World J Gastroenterol WJG. 2013 Feb 21;19(7):97983.

30.Cuocolo R, Caruso M, Perillo T, Ugga L, Petretta M. Machine Learning in Oncology: A Clinical Appraisal. Cancer Lett. 2020 Apr 3. 